\title{
De-adoption and its 43 related terms: harmonizing low-value care terminology
}

\author{
Danijela Gnjidic ${ }^{1^{*}}$ and Adam G. Elshaug 2,3
}

\begin{abstract}
Research into the prevalence and impact of low-value medical practices has evolved substantially over the past two decades. However, despite international efforts, many challenges still remain with regards to progress in this field, including limits in the capacity to identify and prioritize low-value care practices and to systematically appraise clinical and policy attempts at redressing low-value care. A recent article by Niven et al. in BMC Medicine consolidates the current literature and terminology on the de-adoption of clinical practices, advocating the use of de-adoption as an appropriate term to label low-value care and proposes a new synthesis model to facilitate efforts to reverse ineffective and harmful medical practices. We hope that this work will facilitate advances in low-value care research and policy, and shift focus towards establishing evidence for de-adopting low-value interventions, which is crucial since attempts to reduce low-value care interventions have shown mixed results.
\end{abstract}

Please see related article: http://www.biomedcentral.com/1741-7015/13/255

Keywords: De-adoption, Harmful, Ineffective, Low-value care, Medical interventions

\section{Background}

In the 1990s, England's National Institute for Health and Care Excellence co-opted the term 'disinvestment' from industry parlance, heralding its transition to the health sector [1]. Within industrial settings, disinvestment primarily refers to the removal of resources from obsolete items such as machinery. In healthcare settings, there is less scope for such binary verdicts and, as such, more attention is given to the complex issues associated with the ethics of waste reduction. The most common definition places it as "processes of withdrawing (partially or completely) health resources from any existing health care practices, procedures, technologies or pharmaceuticals that are deemed to deliver little or no health gain for their cost, and are thus not efficient health resource allocations" [2], allowing for resource re-allocation. As Niven et al. [3] so aptly indicate, many related concepts are subsumed within misuse, overtreatment, overdiagnosis, overmedicalization, waste, opportunity cost, allocative and/or technical efficiency, resource re-allocation, and de-adoption. Terminological proliferation has ensued

\footnotetext{
* Correspondence: danijela.gnjidic@sydney.edu.au

${ }^{1}$ Faculty of Pharmacy, University of Sydney, Sydney, NSW, Australia

Full list of author information is available at the end of the article
}

for several years, as visualized in the word cloud presented herein (Fig. 1) and derived from the most common terms identified by Niven et al. [3].

The article by Niven et al. [3] represents an important contribution to the field, representing, along with the manuscripts referenced within it, a valuable repository cataloguing the current state-of-the-science from around the world with regards to efforts at reducing the use of low-value healthcare. Throughout article we are reminded that contemporary de-adoption initiatives can be likened to 'old wine in a new bottle', for related programs have emerged and re-emerged since the 1970s [4,5]. While the desire to minimize waste and deliver safe, effective, and efficient healthcare is old wine, the new bottle is represented by ever-evolving research, analysis, health technology assessment methods, and dovetailed policy processes. It is clear that the clinical, research, and policy communities have attended to the successes and failures of the past and are evolving to develop more robust methods moving forward. Further, many of the challenges faced are universal (e.g. sources of resistance to a potential loss function, burden of evidence requirements, levers to encourage optimal use), yet initiatives tend to be context specific: there is no 


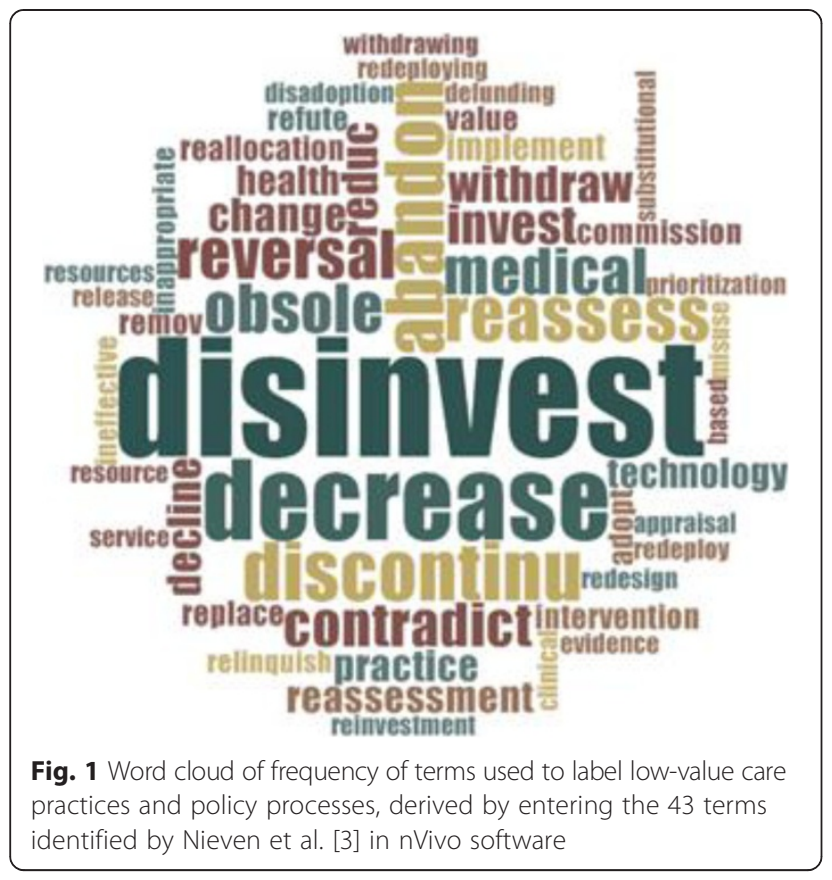

one-size-fits-all approach and, for numerous evolving programs, their success remains uncertain.

Nevertheless, despite increasing international efforts, researchers are still faced with significant challenges with regards to research on low-value clinical practices [6]. Curiously, the ability to identify and prioritize which practices are of low-value appears to have overtaken the ability to systematically evaluate the clinical and policy attempts at reducing low-value care [7]. Indeed, strategies such as Choosing Wisely have been established in the USA, UK, Canada and, recently, Australia to identify and (it is to be assumed) reduce the overuse of interventions considered as low-value. To illustrate some examples of low-value interventions we present the International Choosing Wisely Top 10 list [8].

- Imaging for low back pain

- Stress cardiac imaging for initial evaluation

- Annual stress cardiac imaging

- Pre-op testing before low risk surgery

- Antibiotics for sinusitis

- Benzodiazepines in the elderly

- Long-term proton-pump inhibitor therapy for gastrointestinal symptoms

- Antipsychotics for dementia

- Antimicrobials for bacteriuria in elderly

- Urinary catheters

For instance, overuse of pharmaceutical agents of questionable benefit, such as antipsychotics among people with dementia, has been of particular concern. Despite strong evidence that antipsychotic use is linked with significant harms and that the cessation or deprescribing of antipsychotics is safe, these agents continue to be overused among people with dementia [9]. Efforts are needed to establish evidence-based guidelines for the most effective interventions to deprescribe antipsychotics and other medications of questionable benefit in this patient group [10, 11].

Given this background, Niven et al.'s scoping review [3] consolidates the current literature and terminology on the de-adoption of clinical practices, with the ultimate aim to develop a new synthesis model for providers and decision-makers to facilitate the reversal of ineffective and harmful medical practices. The authors identified 43 different terms used to refer to the process of deadoption, with 'disinvest' (39 \%) and 'decrease use' (24 \%) being the most frequently cited terms. They further recommend that 'de-adoption' should be the term used to standardize the literature on low-value clinical care. Given the increasing focus on generating evidence to inform low-value care practices, we agree that reaching a consensus on the most appropriate term to be used to refer to low-value care is of benefit. We recommend that researchers debate the use of the 'de-adoption' term to standardize the terminology [6]. Interestingly, de-adopt was only cited by $3 \%$ of the included papers. It remains to be seen whether this will impose some barriers to implementing the 'de-adoption' term in the relevant literature.

Niven et al. [3] also indicate that the most prominent low-value care 'red flag' in their sourced studies was that of safety concerns. While legitimate, the onus is on clinicians and researchers to conduct further studies to generate evidence about low-value practices based on their ineffectiveness rather than the red flag of safety alone. To further progress the field, the authors propose a deadoption framework model based on 13 frameworks that conceptualize individual components of a de-adoption process. The question is, how can attention be focused towards the implementation of this framework to guide the de-adoption of ineffective and harmful practices? Each framework component must be considered to understand the issues that underpin this model and be able to answer the question above.

\section{Untangling the de-adoption framework}

Historically, the primary focus lay on identifying lowvalue clinical practices; focus has now shifted to prioritizing selected low-value practices for evidence-based review or reassessment $[7,12]$. The assessment or measurement of the prevalence of low-value practices has recently received significant attention. While these methods are evolving, there remains a need for considerable further measurement worldwide [6]. Additionally, the design and implementation of de-adoption initiatives at the clinical and policy levels is no simple task. Arguably, there is no 
one model to drive this step given that the circumstances of individual healthcare environments are widely varied and context specific [13]. For example, as the recent OECD report reveals [14], individual countries have tackled the problem of cesarean delivery over-use differently, all with varying degrees of success. Niven et al. [3] further emphasize this point in their synthesis. So too, rather than re-inventing the wheel, the adaptation of a knowledge step' in the Niven model is well founded, with growing examples of existing policy processes that can be merged with promising initiatives, thus adding value to the overall process. The next step in their model involves the evaluation of de-adoption processes and outcomes [15]. Without doubt, there is a dearth of information in this domain due to the lack of a publication imperative by policy stakeholders performing this work and/or due to evidence lying in grey literature that is difficult to obtain. Sustaining deadoption initiatives is particularly challenging and it is well regarded in the field that de-adoption is far from merely reversing the implementation process [6]. The last step of this framework, namely the assessment of barriers and facilitators to the de-adoption of interventions, is perhaps the most important. While this framework step has received a great deal of attention from both the clinical and policy analysis perspectives $[2,16,17]$, it remains underrepresented in terms on quantitative evaluation.

\section{Conclusions}

We commend the authors for summarizing the current literature on low-value clinical practices, the terminology used thus far, and the impact of de-adoption interventions. This scoping review substantially contributes to the continuing maturation of low-value clinical practice literature. This is an important step in consolidating the research to date, particularly regarding what constitutes low-value care, and is essential to generate the evidence base for de-adoption approaches of clinical practice.

\section{Competing interests}

Associate Professor Adam Elshaug receives consulting/sitting fees from Cancer Australia, the Capital Markets Cooperative Research Centre - Health Quality Program, NPS MedicineWise (facilitator of Choosing Wisely Australia), and the Australian Commission on Safety and Quality in Health Care, and is a Ministerial appointee to the (Australian) Medicare Benefits Schedule Reviews Task Force.

\section{Authors' contributions}

DG and AE contributed to conception of the article. Both authors were involved in drafting, editing, and revising the manuscript and both agreed to its publication. Both authors read and approved the final manuscript.

\section{Acknowledgements}

Danijela Gnjidic is supported by a National Health and Medical Research Council Early Career Fellowship. Adam Elshaug receives salary support as the HCF Research Foundation Principal Research Fellow.

\section{Author details}

${ }^{1}$ Faculty of Pharmacy, University of Sydney, Sydney, NSW, Australia. ${ }^{2}$ Menzies Centre for Health Policy, University of Sydney, Sydney, NSW, Australia. ${ }^{3}$ Lown Institute, Brookline, MA, USA.
Received: 2 October 2015 Accepted: 8 October 2015

Published online: 20 October 2015

\section{References}

1. Garner S, Littlejohns P. Disinvestment from low value clinical interventions: NICEly done? BMJ. 2011;343:d4519.

2. Elshaug AG, Hiller JE, Tunis SR, Moss JR. Challenges in Australian policy processes for disinvestment from existing, ineffective health care practices. Aust New Zealand Health Policy. 2007:4:23.

3. Niven DJ, Mrklas KJ, Holodinsky JK, Straus SE, Hemmelgarn BR, Jeffs LP, et al. Towards understanding the de-adoption of low-value clinical practices: a scoping review. BMC Med. 2015;13:255.

4. Wirtz V, Cribb A, Barber N. Reimbursement decisions in health policy-extending our understanding of the elements of decision-making. Health Policy. 2005;73:330-8.

5. Mackean G, Noseworthy T, Elshaug AG, Leggett L, Littlejohns P, Berezanski J, et al. Health technology reassessment: the art of the possible. Int J Technol Assess Health Care. 2013;29:418-23.

6. Morgan DJ, Brownlee S, Leppin AL, Kressin N, Dhruva SS, Levin L, et al. Setting a research agenda for medical overuse. BMJ. 2015;351:h4534.

7. Elshaug AG, McWilliams JM, Landon BE. The value of low-value lists. JAMA. 2013;309:775-6.

8. Levinson W. Searching for effective innovations I: reducing low-value care. Webinar. Washington: Academy Health; 2015. http://www.academyhealth.org/ Events/events.cfm?!temNumber=16876. Accessed 10 Jan 2015.

9. Scott IA, Hilmer SN, Reeve E, Potter K, Le Couteur D, Rigby D, et al. Reducing inappropriate polypharmacy: the process of deprescribing. JAMA Intern Med. 2015;175:827-34.

10. Gnjidic D, Le Couteur DG, Hilmer SN. Discontinuing drug treatments. BMJ. 2014;349:97013.

11. Parkinson B, Sermet C, Clement F, Crausaz S, Godman B, Garner S, et al. Disinvestment and value-based purchasing strategies for pharmaceuticals: an international review. Pharmacoeconomics. 2015:33:905-24.

12. Paprica PA, Culyer AJ, Elshaug AG, Peffer J, Sandoval GA. From talk to action: policy stakeholders, appropriateness, and selective disinvestment. Int J Technol Assess Health Care. 2015. Ahead of print.

13. Wilson MG, Ellen ME, Lavis JN, Grimshaw JM, Moat KA, Shemer J, et al. Processes, contexts, and rationale for disinvestment: a protocol for a critical interpretive synthesis. Syst Rev. 2014;3:143.

14. OECD. Geographic variations in health care: what do we know and what can be done to improve health system performance? Focus on Health. Paris: OECD; 2014. http://www.oecd.org/els/health-systems/FOCUS-onGeographic-Variations-in-Health-Care.pdf.

15. Bhatia RS, Levinson W, Shortt S, Pendrith C, Fric-Shamji E, Kallewaard M, et al. Measuring the effect of Choosing Wisely: an integrated framework to assess campaign impact on low-value care. BMJ Qual Saf. 2015;24:523-31.

16. Haas M, Hall J, Viney R, Gallego G. Breaking up is hard to do: why disinvestment in medical technology is harder than investment. Aust Health Rev. 2012;36:148-52.

17. Sheingold S, Sheingold BH. Medical technology in the U.S. healthcare system: is this the road to Abilene? World Med Health Policy. 2010;2:Article 5.

\section{Submit your next manuscript to BioMed Central and take full advantage of:}

- Convenient online submission

- Thorough peer review

- No space constraints or color figure charges

- Immediate publication on acceptance

- Inclusion in PubMed, CAS, Scopus and Google Scholar

- Research which is freely available for redistribution 